\title{
Herrn Prof. Dr. H. R. Schinz zum 70. Geburtstag
}

Am 13. Dezember dieses Jahres begeht Hans Rudolf Schinz, Ordi-narius fur Radiologic an der Medizinischen Fakultat Zurich, seinen 70. Geburtstag. Im Jahre 1948 hat er mit viel Mut und Umsichtigkeit diese Zeitschrift gegriindet. Gleichzeitig wurde die Zeitschrift Organ der Schweiz. Nationalliga fur Krebsbekampfung und Krebsforschung, die er 1953-1956 prasidierte.

In seiner langen Tatigkeit als Arzt, Universitatsprofessor und als Forscher hat der Jubilar viel getan fur die Aufklarung der Krebs-

2

Herrn Prof. Dr. H. R. Schinz zum 70. Geburtstag

ursachen, fiir die Erkennung der Krebskrankheit und fiir die Be-kampfung des Krebsleidens. So liegen von ihm heute zahlreiche und umfassende statistische Untersuchungen vor iiber die Strukturwand-lungen der Bevolkerung, iiber Wandlungen der Todesursachen, der Carcinomhaufigkeit, Carcinomgefahrdung und Carcinomsterblichkeit in der Stadt Zurich, im Kanton Zurich, in der Schweiz, in Deutsch-land und Frankreich.

Zur Intensivierung des Kampfes gegen den Krebs hat Prof. H. R. Schinz als President der SNKK einen Plan entworfen, der die Schaf-fung von kantonalen Ligen als Zentren der ortlichen Krebsbekamp-fung vorsah. Die kantonalen Ligen sollten in erster Linie die Gedan-ken der Friiherfassung des Krebses, wie der Nachkontrollen und Be-handlungsplanung intensivieren. Dieser Plan wurde von der Liga als vorziigliches Arbeitsprogramm anerkannt. In den Jahren 1956-1961 ist es gelungen, in samtlichen Kantonen der Schweiz ortliche Krebs-ligen zu griinden, die nun alle ihre Tatigkeit im Dienste der Mensch-heit aufgenommen haben. Es ist wohl das schonste Geburtstagsge-schenk, das von den Herausgebern, der SNKK wie den taglichen Mitarbeitern Herrn Prof. Schinz uberreicht werden kann.

SNKK, Herausgeber und Mitarbeiter der «Oncologia» mochten Herrn Prof. Schinz herzlich danken und zum 70. Geburtstagsfest gra-tulieren. Sie wunsehen ihm noch viele Jahre erfolgreicher Tatigkeit.

Fiir den Verlag Karger: Th. Karger

Fiir die SNKK: $\quad$ E. Schauenberg, President ab 1961

E. Uehlinger

President 1956-61 R. Franzoni

Generalsekretar L. Herold

Quastor 